\title{
An overview of 16 years of admissions for electrical burns to Burn ICU of "G.Papanikolaou” Hospital, Greece.
}

\section{Author: Dr Joycey Andrew ${ }^{1}$}

Co-authors: Tzimorota Z. ${ }^{1}$, Pagkalos G. ${ }^{1}$, Lavrentieva A. ${ }^{2}$, Demertzis F. ${ }^{1}$, Pantazi G. ${ }^{1}$, Papadopoulou S. ${ }^{1}$, Manos K. ${ }^{1}$

'Department of Plastic, Reconstructive and Hand Surgery \& Burns ICU, General Hospital of Thessaloniki "G. Papanikolaou", Greece

$21^{\text {st }}$ General Intensive Care Unit, “G. Papanikolaou” Hospital, Thessaloniki, Greece

\section{INTRODUCTION}

We will present the demographic data, morbidity and outcomes of patients with electrical burns who were admitted to our four-bed Burns ICU.

-Characteristics of electrical burns in brief:

-A relatively small area of skin thermal injury could be masking disproportionate and extensive damage to underlying and internal tissues.

-A high rate of amputations, as severe damage is localized to the extremities, with entry point of electricity in the upper extremities 70 $85 \%$ and exit point in the lower extremities $50-70 \%$.

- Frequent damage to the cardiovascular and nervous system.

-Destruction of the capillary vessels, leading to secondary tissue necrosis, mainly of the muscles.

-Increasing rate of renal failure, due to the high levels of myoglobin.

\section{Electrical Burns ICU admissions 2001-2016}

In the period 2001-2016, 36 patients $(1 \% / 35$ ऊ) were admitted to our ICU with electrical burns. They represent the $7.9 \%$ of the patients admitted during this period. Most patients were between 15-50 years old $(n=26 / 72 \%)$

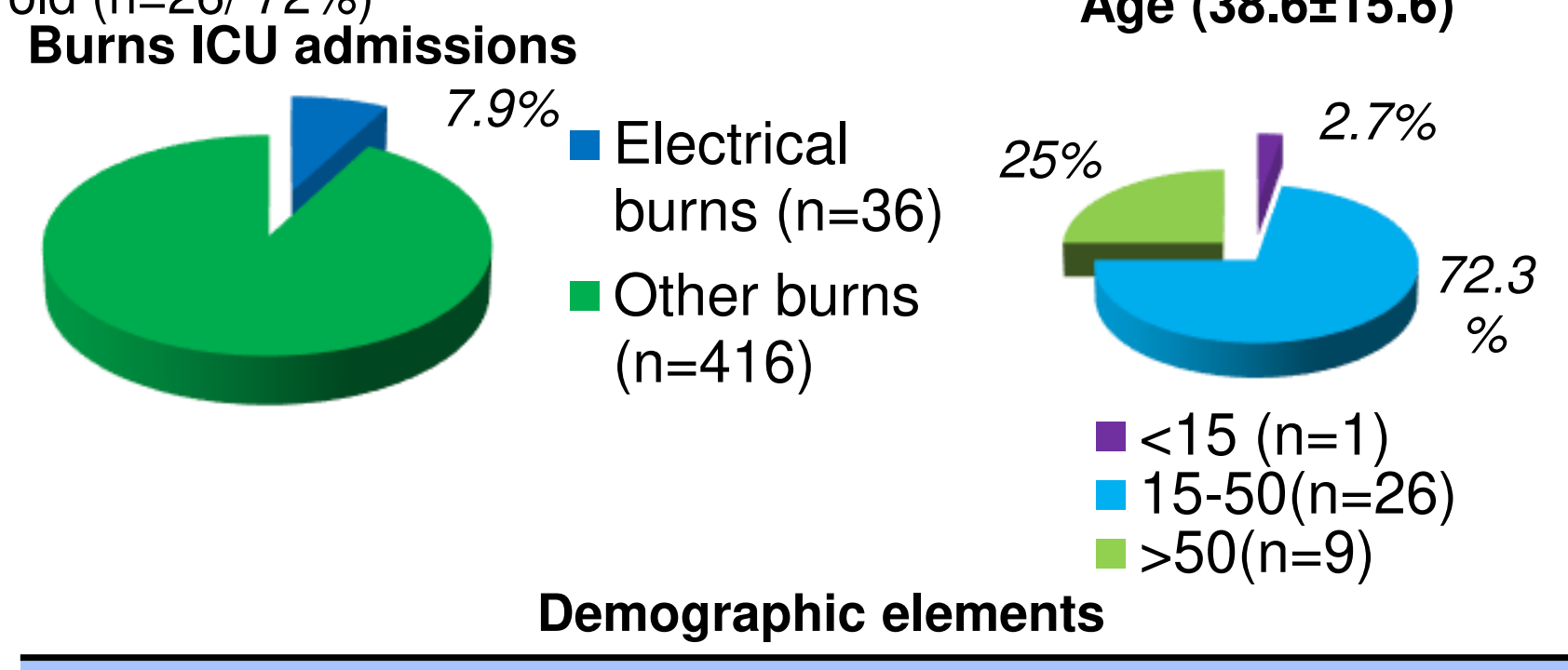

Age (38.6 \pm 15.6$)$

\begin{tabular}{lll}
\hline TBSA \% meantstdev & $28.31 \pm 18.3$ \\
\hline High voltage (> 1000 V) & $\mathrm{n}=14$ \\
Flash injury & $\mathrm{n}=5$ & \\
Low voltage ( $<1000 \mathrm{~V})$ & $\mathrm{n}=22$ & \\
Ethnic minority & $\mathrm{n}=9$ & \\
Uninsured & $\mathrm{n}=11$ & $22 \%$ \\
\hline Causes & Number of patients & $39 \%$ \\
\hline Work related accidents & 8 & $17 \%$ \\
Domestic accidents & 14 & \\
Copper wire theft/ criminal & 6 & $22 \%$ \\
actions & & \\
Undefined causes & 8 & \\
\hline
\end{tabular}

Evaluation of severity on admission

We used the APACHE II, SOFA and SAPS II severity of disease classification systems on admission.

\begin{tabular}{lc} 
Parameter & Mean \pm SD \\
\hline SOFA (Sequential Organ Failure Assessment) & $2.1 \pm 1.2$ \\
APACHE II (Acute Physiology and Chronic & $8.7 \pm 3.1$ \\
health Evaluation) & \\
SAPS II (Simplified Acute Physiology Score) & $28.8 \pm 13,7$ \\
Predicted mortality(APACHE II) & $6 \pm 3.1 \%$
\end{tabular}

Length of stay in ICU: $19.2 \pm 18.1$ days

Duration of intubation and respiratory support: $15.2 \pm 10.4$ days

2 patients died (mortality rate: $5.5 \%)$ :

- Patient 1:10/ 32 (APACHE II/SAPS II), Predicted mortality 4.2\%

- Patient 2:11/34 (APACHE II/SAPS II), Predicted mortality 4.8\%

\section{Surgical procedures required/ Amputations}

All 36 patients required surgical procedures (5 on average/patient). 8 of the patients $(22.2 \%)$, all with high voltage injuries, required one or more amputations.

\section{Procedures}

\section{Nr. of patients}

Escharotomies / fasciotomies

14

Carpal tunnel release

8

Upper limb amputation

8

Hand amputations(phalanx, finger) 9

Lower limb amputation 3

Debridement / allograft $\quad 15$

Debridement / STSG 22

Debridement / FTSG 2

Flap reconstruction 3

Bowel resection 1

High CPK levels were recorded on admission ( mean $31.465 \mathrm{U} / \mathrm{L}$ ) which were managed with urine alkalization (mean $744 \mathrm{U} / \mathrm{L}$ on day 8).The 8 patients that required amputation had distinctively higher CPK levels on admission.

\section{CPK (mean U/L)}

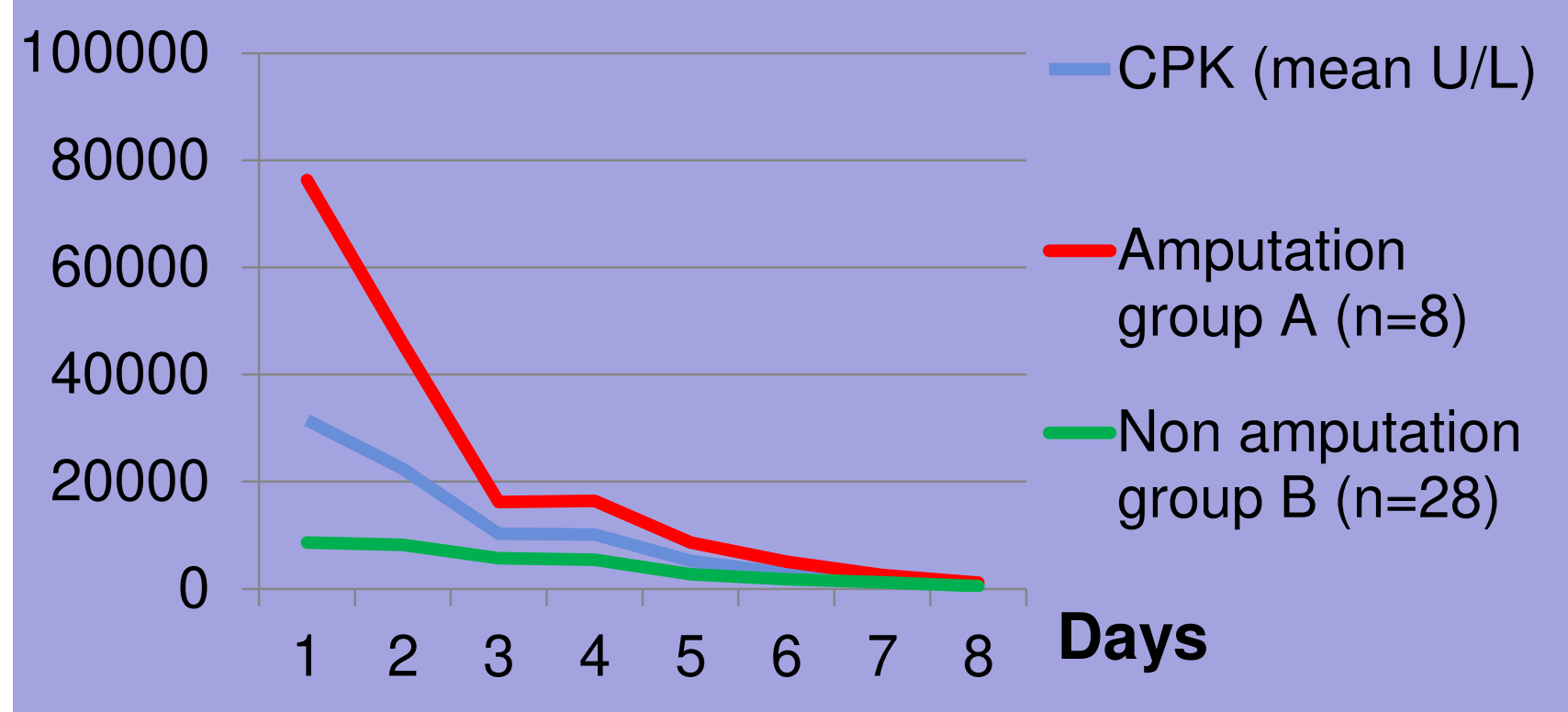

\section{Renal complications}

Using the RIFLE criteria, $3(8.3 \%)$ of our patients developed renal injury and $1(2.7 \%)$ renal failure. The causes for renal damage were associated with the appearance of septic shock and toxicity due to the use of antibiotics. For all 36 patients the Parkland formula was used for fluid resuscitation.

\section{CONCLUSIONS/DISCUSSION}

-Patients with electrical burns account for a small percentage of the patients treated on our Burns ICU.

- Clinical suspicion should be high with electrical burns, as seemingly minor skin burns often leave serious internal tissue damage, with a complex pattern of injury and a variety of clinical manifestations going undetected.

-There is a correlation of CPK levels and the severity of the internal tissue damage, and these may be indicators for predicting the possibility of major amputations required.

-A low mortality rate has been observed $(5.5 \%)$, with the main cause of death being septic shock.

-The most frequent complications were: Infections (8 patients/22\%), Sepsis (3 patients/8\%), and Septic shock (2 patients/ 5.5\%). 